๑) Open Access Full Text Article

\title{
Assessment of prescribing, dispensing, and patient use pattern of antihypertensive drugs for patients attending outpatient department of Hiwot Fana Specialized University Hospital, Harar, Eastern Ethiopia
}

This article was published in the following Dove Press journal:

Drug Design, Development and Therapy

17 January 2015

Number of times this article has been viewed

\author{
Fedila Shukrala' \\ Tesfaye Gabriel ${ }^{2}$ \\ 'Dil Chora Referral Hospital, Dire \\ Dawa, Ethiopia; ${ }^{2}$ Department of \\ Pharmaceutics and Social Pharmacy, \\ School of Pharmacy, College of Health \\ Sciences, Addis Ababa University, \\ Addis Ababa, Ethiopia
}

Background: Hypertension is a global concern and is one of the key preventable risk factors for cardiovascular events, resulting in unnecessary morbidity and mortality. The aim of this study was to assess the prescribing, dispensing and patient use pattern of antihypertensive drugs among patients attending Hiwot Fana Specialized University Hospital outpatient department. Methods: A hospital-based cross-sectional study was conducted in Hiwot Fana Specialized University Hospital on assessment of the prescribing, dispensing, and patient use pattern of antihypertensive drugs among patients who were above the age of 18 years and attending outpatient department from April 1-May 31, 2013. Data collection was conducted by reviewing the record of patients and direct observation of the dispensing process of randomly selected patients to measure average dispensing time, and direct interview with the patients.

Results: A total of 400 patients met the inclusion criteria; out of the 400 patients studied, $63.5 \%$ were females. Most of the patients had Stage 1 hypertension (69\%), followed by Stage 2 hypertension (31\%). Out of the total number of patients, 264 were with different comorbid conditions: diabetes mellitus (64.3\%), followed by congestive heart failure (15.1\%) and ischemic heart disease (2.3\%). The most frequently prescribed class of antihypertensive drugs was diuretics, of which hydrochlorothiazide was the most frequently prescribed drug, both in single (55\%), followed by enalapril (22.3\%), methyl dopa (11.2\%), atenolol (6.9\%), and nifedipine (4.6\%), and in combination with other antihypertensive drugs. The average dispensing time was 1.2 minutes, and $75 \%$ of the patients left the counter with inadequate information about the dosage.

Conclusion: All antihypertensive drugs prescribed were in compliance with the Ethiopian Standard Treatment Guidelines. This study showed that most outpatients with hypertension in our hospital received monotherapy. Diuretics and angiotensin converting enzyme inhibitors were the most frequently prescribed classes of antihypertensive drugs in both monotherapy and combination therapy.

Keywords: hypertension, antihypertensive drugs, monotherapy, combination therapy, fixed dose combination, compliance

\section{Introduction}

\section{Background information}

Hypertension is a major global concern and public health problem affecting more than one billion individuals worldwide and is one of the key preventable risk factors for

Tel +251912049154

Email tesfu.gabriel@gmail.com 
cardiovascular events. It has a massive distributing impact on the population's health, resulting in unnecessary morbidity and mortality. ${ }^{1}$

In nearly $75 \%$ of adults with cardiovascular disease, hypertension is a common morbidity. ${ }^{2}$ Despite the availability of a wide range of antihypertensive drugs, hypertension and its complications are still an important cause of adult morbidity and mortality. 3,4

Factors reported to be contributing to the failure to control blood pressure (BP) include poor adherence to therapeutic regimen, ignorance, and poverty. ${ }^{3,5}$ Recent reports have, however, focused on the role of health care provider and poor adherence to antihypertensive drugs. ${ }^{6}$

One of the most pressing problems facing public health providers and administrators in many countries is the irrational use of drugs, ${ }^{7}$ and, therefore, the concept of rational drug use during the past few years has been the theme of various national and international gatherings. Various studies conducted in developing as well as developed countries during the past few years regarding the safe and effective use of drugs show that irrational drug use is a global phenomenon, and only few prescriptions show rational use of drugs. ${ }^{8}$

The irrational use of drugs is a major problem of presentday medical practice, and its consequences include ineffective treatment, unnecessary prescription of drugs, development of resistance, adverse effects, and economic burden on patients and society. The five important criteria for rational drug use are accurate diagnosis, proper prescribing, correct dispensing, suitable packing, and patient adherence. Therefore, prescribers should make accurate diagnoses and prescribe rationally. Pharmacists should ensure that the effective form of the drug reaches the right patient in the prescribed dosage and should also give clear instructions on the use of the drug. ${ }^{9,10}$ The study of the prescribing pattern is an important part of a medical audit that seeks to monitor the pattern of drug use and necessary modification to the pattern to achieve rational and cost-effective medication use. ${ }^{11}$

The need to improve the global control of high BP necessitated the stipulation of various hypertension classification and treatment guidelines. In recent times, these guidelines include those of the World Health Organization/International Society of Hypertension (WHO/ISH) and the sixth and seventh report of the joint national committee on the prevention, detection, evaluation, and treatment of hypertension. ${ }^{12}$

The aim of this study was, therefore, to assess the prescribing, dispensing, and patient use pattern of antihypertensive drugs in the outpatient department of Hiwot Fana Specialized University Hospital (HFSUH). The prescribing pattern was investigated to ascertain whether it was in accordance with Ethiopian Standard Treatment Guidelines.

\section{Methodology}

Prospective and retrospective studies were conducted in the hospital after obtaining approval from the institutional ethical committee. Permission was also obtained from the head of the hospital to access records. Informed consent was secured as the study involved analysis of records.

Data were collected by evaluating or reviewing the records of 400 patients with hypertension attending HFSUH and by directly observing the dispensing pattern to determine the time of dispensing between the patients and the pharmacists as well as to evaluate the pattern of patient use. Two hundred patients randomly selected were interviewed by using preprepared data collection tools for those who were taking their medication from the pharmacy during April 1-May 31, 2013. The amount of time that the pharmacist spent with the patient while dispensing the prescribed drug was measured by directly observing the dispensing process.

All patients who had hypertension and were actively attending the HFSUH outpatient department were included in the study; however, patients attending the inpatient department, who were under the age of 18, with psychiatric illnesses, who were chronically ill-looking, and manifested hypertensive emergencies, or were nonconsenting were excluded from the study.

Drugs were grouped in major classes of antihypertensive monotherapy - diuretics, beta-blockers (BB), angiotensin converting enzyme (ACE) inhibitors and angiotensin II receptor antagonists (AIIRAs), calcium channel blockers (CCBs), or others. Monotherapy was defined as a prescription for one agent, or two within the same drug class (to cover the widely used fixed-combination formulations). Combination therapy was defined as a prescription for more than one agent from two classes, including two agents in one formulation.

Hypertension was defined as systolic blood pressure $\geq 140 \mathrm{mmHg}$ and diastolic blood pressure $\geq 90$, or being on drug therapy. Stage 1 blood pressure was defined as BP in the range 140-159/90-99, and Stage 2 blood pressure as BP in the range $\geq 160 / \geq 100$. Prehypertension was not considered to be a disease category.

The prescribing pattern was compared with the Ethiopian Standard Treatment Guidelines, which suggest that any one of the following classes of drugs could be used as first-step agents against hypertension based on nonemergency and emergency conditions: diuretics, beta-blockers, calcium antagonists, and converting enzyme inhibitors, and the drugs 
prescribed were also checked to ascertain whether they were on the List of Essential Medicines for Ethiopia or not.

\section{Results}

Among the 400 patients studied, $63.5 \%$ and $36.5 \%$ were females and males, respectively. Most of them fell in the age group of 51-60 years. The majority of the patients (69\%) had Stage 1 hypertension, and $31 \%$ had Stage 2 hypertension (as shown in Table 1). Out of the total number of patients, 132 had comorbid conditions, and 85 were on monotherapy, namely, diabetes mellitus (64.3\%), followed by congestive heart failure (CHF) (15.1\%), and ischemic heart disease (ISHD) $(2.3 \%)$. The remaining $18.3 \%$ had other infectious diseases as comorbid conditions. The highest number of prescriptions were ordered by health officers $(212 ; 53 \%)$, followed by prescriptions ordered by nurses $(110 ; 27.5 \%)$, medical doctors $(40 ; 10 \%)$, and medical and $\mathrm{HO}$ interns $(38 ; 9.5 \%)$, as indicated in Figure 1.

Of the 400 patients studied, $260(65.5 \%)$ were on monotherapy, while $140(34.5 \%)$ were on combination therapy. Sex-wise, 163 females received monotherapy, and 49 males were on combination therapy. The pattern of prescription of antihypertensive drugs is shown in Table 2 . The most frequently prescribed class of antihypertensive drugs was diuretics, of which hydrochlorothiazide (HCT) was the most frequently prescribed drug, both in single (55\%), followed by enalapril (22.3\%), methyl dopa (11.2\%), atenolol (6.9\%), and nifedipine (4.6\%), and in combination with other antihypertensive drugs. A two-drug combination appeared to be the most frequent dose combination, of which the HCT-Enalapril combination comprised more than half (57\%). Twenty-seven and half percent and $72.5 \%$ of the two-drug combination regimen were prescribed in Stage 1 hypertension and Stage 2 hypertension, respectively.

A total of 1,280 drugs were prescribed, and the average number of drugs prescribed per encounter was $3.2 \pm 0.93$. Out of 544 antihypertensive drugs prescribed, 527 (97\%)

Table I Demographic characteristics of hypertensive patients on antihypertensive drugs in HFSUH outpatient department, April I-May 31, 2013

\begin{tabular}{|c|c|c|c|c|}
\hline \multirow{2}{*}{$\begin{array}{l}\text { Age } \\
\text { (years) }\end{array}$} & \multicolumn{2}{|l|}{ Sex } & \multirow{2}{*}{$\begin{array}{l}\text { Total } \\
\text { (males }+ \\
\text { females) }\end{array}$} & \multirow{2}{*}{$\begin{array}{l}\text { Percentage of } \\
\text { hypertensive } \\
\text { patients (\%) }\end{array}$} \\
\hline & Males & Females & & \\
\hline $18-30$ & 5 & 23 & 28 & 7 \\
\hline $31-40$ & 15 & 39 & 54 & 13.5 \\
\hline $4 I-50$ & 28 & 80 & 108 & 27 \\
\hline $51-60$ & 57 & 67 & 124 & 31 \\
\hline$>60$ & 41 & 45 & 86 & 21.5 \\
\hline Total & 146 & 254 & 400 & 100 \\
\hline
\end{tabular}

Abbreviation: HFSUH, Hiwot Fana Specialized University Hospital. were prescribed in accordance with Ethiopian Standard Treatment Guidelines, and 473 (87\%) were prescribed by their generic name. All antihypertensive drugs were prescribed from the list of essential medicines.

The average dispensing time for each patient was 1.5 minutes. Out of 200 patients who were interviewed after dispensing, only 13 (6.5\%), 52 (26\%), 58 (36\%), 11 (5.5\%), and $26(13 \%)$ knew the names of the drug, dose of the drug, frequency of dosing, side effects of the drugs they were taking, and caution to take during the treatment regimen, respectively.

\section{Discussion}

The results of the present study indicate that the proportion of females with hypertension (63.5\%) was high. Other studies have also revealed that there was a high incidence of hypertension among females. ${ }^{4,13}$ More than half of the patients were over 51 years old, showing that higher age was directly related to a higher incidence of hypertension. Among the various possibilities, this could be attributable to the lack of awareness of hypertension and the lack of control of hypertension in old age.

A study conducted by Shivashankaramurthy et $\mathrm{al}^{14}$ in India revealed that $80 \%$ had hypertension (HPN) with edema, unlike our study, which indicated that most of the patients had HPN with diabetes mellitus as the prevalent comorbid illnesses.

This study showed that most outpatients with hypertension in the hospital received monotherapy, although international guidelines ${ }^{2}$ indicated that monotherapy achieves the BP target only in a limited number of hypertensive patients. Earlier studies ${ }^{2,11,15}$ suggested that an ideal combination therapy must include antihypertensive drugs possessing complementary modes of action that produce synergistic antihypertensive effects without any adverse effects, at low

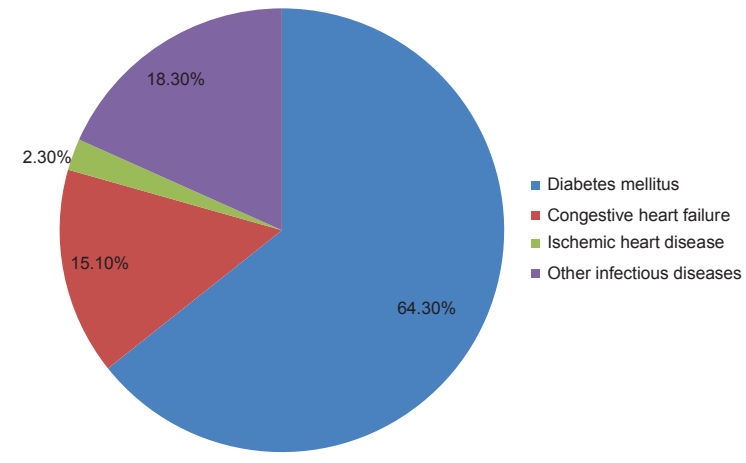

Figure I Prevalence of comorbid conditions among hypertensive patients attending HFSUH outpatient department, April I-May 3I, 2013.

Abbreviation: HFSUH, Hiwot Fana Specialized University Hospital. 
Table 2 Combination antihypertensive therapy for hypertensive patients in HFSUH outpatient department, April I-May 3I, 20I3

\begin{tabular}{llll}
\hline Combination type & Class of drugs & Specific drugs & $\begin{array}{l}\text { Patients on } \\
\text { combination therapy, } \\
\text { number (\%) }\end{array}$ \\
\hline Two-drug combination & Diuretics + ACE inhibitor & HCT + Enalapril & $81(57)$ \\
& Diuretics + CCB & HCT + Nifedipine & $35(26.1)$ \\
& Diuretics + Central alpha agonist & HCT + Methyl dopa & $20(14.5)$ \\
Three-drug combination & Diuretics + ACE inhibitor + CCB & HCT + Enalapril + Nifedipine & $4(1.4)$ \\
Total & & & $140(100)$ \\
\hline
\end{tabular}

Abbreviations: ACE, angiotensin converting enzyme; CCB, calcium channel blockers; HCT, hydrochlorothiazide; HFSUH, Hiwot Fana Specialized University Hospital.

doses. A study conducted by Beg et a ${ }^{15}$ revealed that the proportion of patients on combination therapy was higher than that of those monotherapy.

The choice of diuretics as the first-line antihypertensive drug in our setting was consistent with other studies done by Etuk et $\mathrm{a} \mathrm{l}^{16}$ and in compliance with the current Ethiopian Standard Treatment Guidelines. ${ }^{17,18}$ Another study conducted by Khurshid et $\mathrm{l}^{19}$ in India also reported that diuretics were the most frequently prescribed antihypertensive drugs, a finding similar to our own. The JNC 7 report recommends that in the absence of any specific indications, a diuretic or $\beta$-blocker should be selected as the initial therapy for hypertension. ${ }^{20}$ A thiazide diuretic should be prescribed in the absence of an indication for any other specific drug(s) or when target BP has not been attained. ${ }^{21}$ However, Khaja et al ${ }^{22}$ reported that $\mathrm{BB}(65.5 \%)$ were the most frequently prescribed and that diuretics (27.4\%) ranked second with respect to overall utilization pattern. Diuretic and BB monotherapy accounted for almost $55 \%$ of first-line treatment in the study done by Walley et $\mathrm{a}^{23}$ in the UK.

From the combination therapy, our study showed Diuretics + ACE Inhibitor (57\%) and Diuretics + CCB $(26.1 \%)$ were the most frequently prescribed classes of antihypertensive drugs; however, the study done by Shivashankaramurthy et $\mathrm{al}^{14}$ showed CCB + BB (43.9\%) was frequently prescribed, followed by AIIRAs and diuretics (22.94\%). Beg et al ${ }^{15}$ reported that most commonly prescribed antihypertensive agents were AIIRAs and ACE inhibitors. In the study by Odili et $\mathrm{al}^{24}$, almost half of the subjects (49\%) were on a two-drug combination regimen, and $14 \%$ were on monotherapy; $\mathrm{CCB}$ were the most frequently prescribed classes of drugs (31\%), followed by diuretics (30\%). In the same study, ${ }^{24}$ diuretics were the commonest in combination regimen (74\%). It is reported that a $\mathrm{BB}$ diuretic combination is diabetogenic and should be avoided, especially in obese individuals and those with a family history of diabetes mellitus, ${ }^{21}$ but there was a practice of prescribing such a combination therapy for patients with diabetes mellitus in our setting.
It was observed in our study that there was a low frequency of prescription administration of $\mathrm{BB}$ and $\mathrm{CCB}$ as monotherapy. Furthermore, none of the patients was on AIIRAs either in monotherapy or in combination therapy. The results of our study also showed that there was high prevalence of Stage 1 hypertension (69\%).

It was found that the number of drugs prescribed increased with severity of disease and with different comorbid conditions. The study also showed that the average number of drugs prescribed per encounter was $3.2 \pm 0.923$. Around half of the patients $(53 \%)$ had received their medications upon the orders of Health Officers, and the least were ordered by Medical and Health Officer Interns. Out of 544 antihypertensive drugs prescribed, 527 (97\%) were prescribed in accordance with Ethiopian Standard Treatment Guidelines, and $473(87 \%)$ were prescribed by their generic name. The use of generic names could decrease the financial burden on the patient, and this could show there was a rational prescribing pattern in the setting. Another study done by Beg et $\mathrm{al}^{15}$ revealed that the average number of drugs per prescription was 2.83 . The average time spent between patient and pharmacist during dispensing was 1.23 minutes in our study.

According to our study, greater than $75 \%$ of the patients left the counter without knowing the names of the drugs, side effects, and precautions associated with their medications. This may be because the pharmacists did not take the time to tell the patients about the drug while dispensing. It may also be because most of the patients came from rural areas and were illiterate, so that could have made it difficult for them to read and understand the drugs they were treated with.

\section{Conclusion}

All antihypertensive drugs prescribed were consistent with the Ethiopian treatment guidelines for hypertension. This study also showed that most outpatients with hypertension in our hospital received monotherapy. Diuretics and ACE inhibitors were the most frequently prescribed drugs in both monotherapy and combination therapy. The highest number 
of prescriptions were ordered by Health Officers, and the fewest were by medical and HO interns. Most patients left the counter with inadequate information about the dosage regimen.

\section{Acknowledgments}

We extend our gratitude to the pharmacists and nurses working at Hiwot Fana Specialized University Hospital for their kind assistance during data collection, and to Haramaya University for financial support.

\section{Disclosure}

The authors report no conflicts of interest in this work.

\section{References}

1. Kannel WB. Blood pressure as a cardiovascular risk factor: prevention and treatment. JAMA. 1996;275:1571-1576.

2. Ker J. Combination treatment for hypertension. SA Fam Pract. 2010;52(5):417-421.

3. Isezuo SA, Omotoso ABO, Gaye A, Corrah T, Araoye MA. One year survival among sub-Saharan Africans with hypertensive heart failure. Trop Cardiol. 2000;26:57-60.

4. Cappuccio FP, Micah FB, Emmett L, et al. Prevalence, detection, management, and control of hypertension in Ashanti, West Africa. Hypertension. 2004;43:1017-1022.

5. Hyman DJ, Pavlik VN. Characteristics of patients with uncontrolled hypertension in the United States. N Engl J Med. 2001;345:479-486.

6. Chobanian AV, Bakris GL, Black HR. Seventh report of the Joint National Committee on Prevention, Detection, Evaluation, and Treatment of High Blood Pressure. Hypertension. 2003;42:1206-1252.

7. Thomas M, Alexander B, Tony S, Andrei Z. Guidelines for Implementing Drug Utilization Review Programs in Hospitals. Arlington,VA Moscow, Russia; 1997.

8. Gautam CS, Aditya S. Irrational drug combinations: need to sensitize undergraduates. Indian J Pharmacol. 2006;38(3):169-170.

9. Topno I, Chennama B, Yugandhar B, Balakrishnan S. Antibiotic prescribing pattern in ophthalmology outpatient department in a tertiary care hospital. J Pharmacol Pharmacother. 2012;3:190-191.

10. Vijayakumar TM, Sathyavati D, Subhashini T, Grandhi S, Dhanaraju MD. Assessment of prescribing trends and rationality of drug prescribing. Intern J Pharmacol. 2011;7:140-143.
11. Tiwari H, Kumar A, Kulkarni SK. Prescription monitoring of antihypertensive drug utilization at the Panjab University Health Centre in India. Singapore Med J. 2004;45:117-120.

12. Calhoun DA, Jones D, Textor S, et al. Resistant hypertension: diagnosis, evaluation, and treatment: a scientific statement from the American Heart Association Professional Education Committee of the Council for High Blood Pressure Research. Hypertension. 2008;51:1403-1419.

13. Kearney PM, Whelton M, Reynolds K, Muntner P, Whelton PK, He J. Global burden of hypertension: analysis of worldwide data. Lancet. 2005;365(9455):217-223.

14. Shivashankaramurthy, Kiran LJ, Gokul, Santhosh R, Abhishek A, Prabhakar A. Prescribing patterns of anti-hypertensive combinations in a tertiary care setting. Drug Inven Today. 2011;3(11):265-269.

15. Beg MA, Dutta S, Varma A, et al. Study on drug prescribing pattern in hypertensive patients in a tertiary care teaching hospital at Dehradun, Uttarakhan. Int J Med Sci Public Health. 2014;3:922-926.

16. Etuk E, Isezuo SA, Chika A, Akuche J, Ali M. Prescription pattern of anti-hypertensive drugs in a tertiary health institution in Nigeria. Ann Afr Med. 2008;7(3):128-132.

17. Yusuff KB, Balogun OB. Physicians' prescribing of antihypertensive combinations in a tertiary care setting in southwestern Nigeria. J Pharm Pharmaceut Sci. 2005;8:235-242.

18. Food, Medicine, Health Care Administration and Control Authority (FMHACA). Standard Treatment Guidelines for Zonal Hospitals, Hypertension. Ethiopia, Africa: Food, Medicine, Health Care Administration and Control Authority (FMHACA); 2008:212-217.

19. Khurshid F, Aqil M, Alam MS, Kapur P, Pilla KK. Antihypertensive medication prescribing patterns in a university teaching hospital in South Delhi. Int J Pharm Sci Res. 2012;3(7):2057-2063.

20. Chobanian AV, Bakris GL, Black HR, et al; the National High Blood Pressure Education Program Coordinating Committee. Seventh Report of the National Committee on Prevention, Detection, Evaluation and Treatment of High BP: the JNC 7 report. JAMA. 2003;289:2560-2572.

21. Mpe MT. Choosing antihypertensive treatment for a South African population. SA Fam Pract. 2007;49(8):27-30.

22. Khaja KA J, Sequeira RP, Wahab AW, Mathur VS. Antihypertensive drug prescription trends at the primary health care centres in Bahrain Pharmacoepidemiol Drug Saf. 2001;10(3):219-227.

23. Walley T, Duggan AK, Haycox AR, Niziol CJ. Treatment for newly diagnosed hypertension: patterns of prescribing and antihypertensive effectiveness in the UK. $J R$ Soc Med. 2003;96:525-531.

24. Odili VU, Oghagbon EK, Ugwa NA, Ochei1 UM, Aghomo OE. Adherence to international guidelines in the management of hypertension in a tertiary hospital in Nigeria. Trop J Pharmaceut Res. 2008;7(2):945-952.

\section{Publish your work in this journal}

Drug Design, Development and Therapy is an international, peerreviewed open-access journal that spans the spectrum of drug design and development through to clinical applications. Clinical outcomes, patient safety, and programs for the development and effective, safe, and sustained use of medicines are a feature of the journal, which has also been accepted for indexing on PubMed Central. The manuscript management system is completely online and includes a very quick and fair peer-review system, which is all easy to use. Visit http://www.dovepress.com/testimonials.php to read real quotes from published authors. 